\title{
Kinesin-Like Protein KIF1B
}

National Cancer Institute

\section{Source}

National Cancer Institute. Kinesin-Like Protein KIF1B. NCI Thesaurus. Code C152004.

Kinesin-like protein KIF1B (1816 aa, 204 kDa) is encoded by the human KIF1B gene. This protein plays a role in intercellular transport of organelles and vesicles. 